\title{
Method of reference image selection to provide high-speed aircraft navigation under conditions of rapid change of flight trajectory
}

\author{
NataliiaYeromina $^{1 *}$, Volodymyr Tarshyn ${ }^{2}$, Sergey Petrov $^{3}$, Valery Samoylenko ${ }^{4}$, Iryna Tabakova ${ }^{5}$, \\ Oleh Dmitriiev ${ }^{6}$, Kateryna Surkova ${ }^{6}$, Oksana Danylko ${ }^{6}$, Nadiia Kushnierova ${ }^{6}$, Mykhailo Soroka ${ }^{6}$, \\ Nataliia Salo ${ }^{6}$ and Oleksandr Chumak ${ }^{6}$ \\ Department of Electronic Computers, Kharkiv National University of Radio Electronics, Ukraine, Kharkiv ${ }^{1}$ \\ Professor and Head of the Department of Armament of Radar Troops, Ivan Kozhedub Kharkiv University of Air \\ Force, Ukraine ${ }^{2}$ \\ Department of Physics, Electrical Engineering and Power Engineering, Ukrainian Engineering Pedagogics \\ Academy, Ukraine ${ }^{3}$ \\ National Academy of the National Guard of Ukraine, Ukraine ${ }^{4}$ \\ Department of media systems and technologies, Kharkiv National University of Radio Electronics, Ukraine ${ }^{5}$ \\ Flight Academy of the National Aviation University, Ukraine ${ }^{6}$
}

Received: 19-September-2021; Revised: 22-December-2021; Accepted: 23-December-2021

(C)2021 NataliiaYeromina et al. This is an open access article distributed under the Creative Commons Attribution (CC BY) License, which permits unrestricted use, distribution, and reproduction in any medium, provided the original work is properly cited.

\begin{abstract}
It is reasonable to find a new approach to the selection of the Reference Image (RI) to determine the spatial position of Unmanned Aerial Vehicles (UAVs) with Correlation-Extreme Navigation System (CENS). The selection has to be made from a set of images available on board. This is due to the need to increase the speed of secondary processing of information by the CENS. This is due to high flight speeds and possible intensive maneuvering of UAVs. The use of multi-spectral sensors with different resolution also leads to the need to increase the speed of secondary processing systems of combined CENS. The paper presents an improved model of the Decisive Function (DF) formation process for a set of reference images. Using this model, the problem of method and algorithm development for rational choice of RI in the CENS secondary processing system is formulated. The results of the development of an iterative method and algorithm for the selection of RI from the set of RI recorded on board the UAV is presented. The method consists in the use of iterative procedure of RI selection from the multidimensional matrix representation of the set of RI for different altitudes. Then the selection is carried out according to the angular parameters. The effectiveness of the method was confirmed by simulations. The simulation was performed using the brightness distribution of a typical fragment of the Sighting Surface (SS) image. Influence of observation conditions and sensors' resolution on the difference between the fragments of the Current Image (CI) and the reference image was studied. An algorithm for the rational choice of the RI based on the proposed method was developed. It is shown that the computational complexity of image matching in the CENS can be reduced by tens of times without loss of accuracy in determining the spatial position of an UAV. The application of the algorithm developed for the example considered in the article allows to reduce the computational complexity by 210 times.
\end{abstract}

\section{Keywords}

Aircraft, Sighting surface, Reference image, High speed, Sensor resolution, Ambiguity, Iteration.

\section{Introduction}

Inertial Navigation Systems (INS) are currently used in manned and unmanned aerial vehicles as the main navigation system.

*Author for correspondence

1621
In these systems, the current position of the aircraft is determined by the initial coordinates and the result of double integration of the acceleration vector or single integration of the velocity vector [1].

Inertial navigation systems have high noise immunity, independence of functioning from the time of year and day, all-weather. However, a fundamental disadvantage of these systems is the accumulation 
over time of an error in determining the coordinates relative to the starting point $[1,2]$. Various auxiliary systems are used to provide the required accuracy of Unmanned Aerial Vehicles (UAV) navigation [1, 3]. An important place among these systems is occupied by Technical Vision Systems (TVS), the principle of operation of which is based on determining the navigation parameters of the UAV by using information about natural geophysical fields. Most often used are the terrain field, optical, radar, radiometric image of the sighting surface, the anomalous magnetic field of the earth, the gravitational field of the earth and others [1, 4]. Information from the TVS sensors is used to correct the INS [5]. Measurement of navigation parameters of the TVS is based on comparison of the Current Image (CI) of reference objects on the Earth's surface in the area of application of UAVs with one or more images of the reference representation of the object. These images are referred to as Reference Images (RI). The Cross-Correlation Function (CCF) is most often used as an indicator of image similarity [3]. Correcting systems, which calculate $\mathrm{CCF}$, are called Correlation-Extreme Navigation System (CENS) [3, 5]. Practical realization of these systems is connected with complexity of matching in time and space of images from TVS sensors with known and prepared $\mathrm{RI}$ in advance. When combining images, the current coordinates of the spatial position of the UAV and the orientation angles of the TVS sensors must be taken into account. This is due to the uncertainty in the choice of the RI at definition of current coordinates of UAV and positioning of information sensors.

For the studies described in [5], the degree of coincidence of the current image with the RI depends on a number of errors:

- error in determining the spatial position of the UAV;

- error in determining the altitude of an UAV;

- orientation error of the TVS sensors;

- mapping error.

The total error can be up to $35 \ldots 45 \mathrm{~m}$ on the spatial coordinates It is noted that the difference of real images of sighting surface from the RI increases with decreasing altitude [6]. At an altitude of $100 \mathrm{~m}$ an error can reach a value of 1 radian, whereas necessary errors of images matching must not exceed 0.005 radians horizontally and vertically in the image center [7]. To match images in real time by full search method, it is necessary to compare $105 . .106$ views of the current image and the RI per second. This exceeds the performance of classical computational architecture by more than 103 times [7].

In [8] it is shown that it is impossible to solve the problem of real-time image comparison using the method of full search of all possible angles for RI and CI in six-dimensional space (latitude, longitude, altitude, roll, heading, pitch). It is shown that the number of discrete values for coordinates - 10, and 5 for angles, a complete search should have $\mathrm{N}=$ 125000 variants of views of the RI. It is impossible to perform such a number of alignments in real time. At the same time known results of researches do not take into account complication of a task of comparison of the CI and RI at high speed and intensive maneuvering of the UAV. The decision of this problem gets even more urgency in view of application of UAVs in modern military conflicts. The intensive use of UAVs was recorded during military conflicts in the Caucasus, Ukraine and Syria. The task of image matching in real time has several variants of the solution: application of high-speed onboard calculators; improvement of methods and algorithms of formation of RI, as well as methods and algorithms of comparison of images.

The first variant of solving the problem leads to complicating the onboard calculator, increasing its weight and cost. The second variant of the problem solution is presented in the known publications [919]. However, the comparison of images by the brute-force method does not allow us to obtain the effect of reducing the computational complexity of the formation of correction signals. The most preferable variant is the one considered in $[5,6,8]$. However, the definition and maintenance of the horizon line is impossible at intensive maneuvering of the UAV. According to the authors, a significant reduction in computational complexity in correlation comparison of images can be achieved by rationally selecting a single fragment of the RI from the set of images on board the UAV and iteratively refining the position of the global maximum of the CCF. This approach requires additional research on the development of a method and algorithm for the rational selection of the RI from a set of images and the subsequent comparison of the RI with the CI.

The aim of this paper is to decrease the computational complexity of correlation-extreme image matching based on the development of a method and an algorithm for the rational choice of RI from a set of images. 
The development of the method is an important contribution to the development of the CENS secondary processing systems, which are used in UAVs at high speeds and intensive maneuvering.

\section{Literature review}

In [1] the feasibility of using Freeform Inertial Navigation Systems (FINS) in UAVs when solving problems of cargo delivery, monitoring of various territories. The advantages and disadvantages of these systems are formulated. It is noted that the main advantage of FINS is complete autonomy, but a significant disadvantage is the unlimited growth of error, even for a static object. The results of a comparative analysis of FINS by accuracy classes are presented. Physical and algorithmic methods of improving FINS are considered. It is shown that the physical method allows to reduce the rate of error accumulation, but is not able to reduce it to zero.

Application of algorithmic methods based on combination with other measuring systems allows to reduce the errors of the INS. It is noted that satellite navigation systems and vision systems can be used for integration with INS, which will greatly increase the accuracy of aircraft navigation.

In [2] the principles of construction of various navigation systems, basics of theory and principles of their application are described in detail. The advantage of the work is the results of a detailed analysis of the measurement systems with which it is possible to supplement INS to improve the accuracy characteristics of aircraft navigation systems. As a drawback, it should be noted the absence in this material of specific technical solutions and assessments of the joint use of INS with augmentation systems.

In work [3] results of research of principles of construction and functioning of matrix radiometric correlation-extreme systems of aircraft navigation on ground objects - landmarks, methods of increasing accuracy and probability of determination of coordinates of objects by navigation systems. Analytical solutions and numerical characteristics of potential accuracy of aircraft positioning, results of methods and algorithms of determining the decisive function as a result of images superposition, numerical estimates of accuracy of positioning by radiometric systems of millimeter range based on simulation, results of the assessment of the impact on the probability of positioning the scale and mutual rotation of current and RIs are the undoubted advantages of the work. The disadvantages of the work are that the obtained solutions, theoretical estimates of accuracy and probability of positioning were made by the authors for the case of using on board the aircraft one RI, which does not allow to take into account the influence of sighting geometry conditions, variations of possible angles of RI and CI in six-dimensional space on six degrees of freedom, and, therefore, realism in real time.

The paper [4] presents the results of the analysis of technical problems, which the authors had to face during the development and research of the autonomous navigation complex, as well as the obtained results, starting from hardware design and embedded programming to navigation and mapping based on vision, as well as an overview of the operation of all modules and their integration into the final system. Experimental results are presented demonstrating autonomous navigation of three Micro-Aviation Vehicles (MAV) in an unknown environment, without a Global Positioning System (GPS), but using 3-D mapping and optimal observation coverage. The merits of the work include the development of a new six-rotor platform resistant to single rotor failures, the development of a platform resistant to single rotor failures, equipped with sufficient computing power for on-board computer vision. In addition, the authors were able to carry out the development of a local navigation module, which works in real time on board the MAV. The disadvantage of the work is a complete lack of information about the possibility of using the proposed approach for the navigation of aircraft moving along a complex trajectory with high speeds.

In [5] approaches to the solution of key problems in the development of a combined vision system for aviation, which combines the best properties and functional characteristics of the two systems: a system of enhanced vision, which forms an improved and complex image from several multispectral sensors of vision system, and a system of synthetic vision, which forms an image of a virtual model of the area of digital map, navigation and piloting parameters of aircraft. The advantage of the work is the development of algorithmic methods to reduce the complexity of the image overlay problem based on geometric matching, the need for which is associated with map errors and navigation errors, and visualization of geometrically combined images, taking into account the stage of flight task and visibility conditions. The disadvantage of the work is 
the impossibility of using the developed methods without the pilot's participation.

In [6] issues of reducing computational complexity of combining heterogeneous images in the system of combined vision of the aircraft are considered. The merit of the work is the solutions proposed by the authors, which allow reducing the computational complexity of correlation-extreme matching to the possibility of performing it in real time. In order to avoid oversampling by heading, it was proposed to build a large-size terrain RI. To avoid roll and pitch overshoot, use horizon line or non-correlation rollmatching. The main idea of uncorrelated roll and pitch matching is to find the real horizon line and combine it with the synthesized one. The performance of the algorithm for overlapping the image data of $704 \times 576$ pixels by roll was estimated, with a measurement of $0.014 \mu \mathrm{s}$. This time was obtained by executing the algorithm on a single core of AMD Phenom II $3.1 \mathrm{GHz}$ processor. The processing of 25 frames/c takes 0.04 s to combine a pair of images. The authors show that preprocessing one frame with $704 \times 576$ pixels by the presented methods on the test bench (one core of Phenom-II CPU, 3GHz, 10GFlops) is executed on average in $0.42 \mathrm{~s}$, which is $\sim 14.14$ times more than the required time. It is found that it is possible to perform realtime matching using a single graphics chip supporting Open CL technology. The disadvantage of the work is the limited practical application, on unmanned aircraft, at low flight altitudes due to the inexpediency of using large-sized RI, as well as the impossibility of determining the horizon line for steep trajectories.

In [8] the results of a study of the genetic algorithm in order to obtain the optimal settings when it is used in combined vision systems. It is shown the feasibility of using extended angles of RI in the search for a global extremum. It is shown that when using this approach, the performance of the system increases by a factor of 5 . At the same time, which is a disadvantage, the authors have not taken into account the influence of possible angles of RI and CI on real-time implementation.

In [9-18] the results of studies devoted to the synthesis of RIs different in information content and their comparison with the current image are presented. Methods of advance and operative preparation of RIs on the basis of the use of various invariants are offered. When developing methods for constructing selective images, only the object composition of the sighting surface was taken into account. Such an approach made it possible to form RI by the most informative objects. It was assumed that the comparison of RI with the formed onboard CI would be carried out by the "sliding window" method, and the formation of the comparison result for the correction of the navigation object location would be carried out by a single RI. That is, these methods have limited application, which is their significant disadvantage, since they were not aimed at reducing the computational complexity of image comparison, they did not take into account the volume of arrays of terrain images and the need to form a set of images, taking into account possible changes of angles of formation of CI on board the aircraft.

In [19] a method of forming a set of RI for highprecision navigation of mobile robots was proposed. It is shown that it is necessary to ensure the correlation connection between the neighboring RI not lower than $0.5 \ldots 0.7$. The disadvantage of the method developed in this work is its limited application for solving the problem of navigation of mobile robots moving along trajectories without significant changes in the flight height and sighting angles.

In order to achieve the set goal, the following tasks had to be solved:

1. Refine the model of the decision function formation process, taking into account the navigation of high-speed maneuvering aircraft. To solve the problem of developing a method and algorithm for choosing the RI in the system of secondary processing of the CENS.

2. To develop a method and algorithm for selecting $\mathrm{RI}$ in the secondary processing system of the CENS for navigation of high-speed maneuvering aircraft.

\section{Methods}

The method of rational choice of RI in the system of secondary processing of CENS for navigation of maneuvering aircraft implies a two-stage reduction of RI sampling, used in the correlation analysis of images. At the first stage it is achieved by the formation of partial decisive functional for some value of altitude, received from altimeter of aircraft and the subsequent iterative refinement of value of aircraft altitude, as an argument of maximum of partial mutual correlation function of two images. In the same way at the second stage for obtaining the value of altitude by iteration by partial decisive 
mutual correlation functions the specification of aircraft orientation (according to angular parameters) is made.

Realization of two-step procedure allows to define the true location of the aircraft by comparing a limited set of RI with generated onboard CI of the aircraft. Thus, there is no necessity of comparison of CI with fragments of RI on the remaining coordinates as the correspondence of the compared images on height and angular parameters will provide the correspondence on other coordinates also. A block diagram of the method implementation is shown in Figure 1.

The set of RI- $\mathrm{RI}_{111} \ldots \mathrm{RI}_{\mathrm{BVC}}$ is represented as a threedimensional matrix, in which each individual element $\mathrm{RI}_{\mathrm{bvc}}$ is an $\mathrm{RI}$ (for a particular position in space of the LA). B, V, C-dimensions of the three-dimensional matrix.

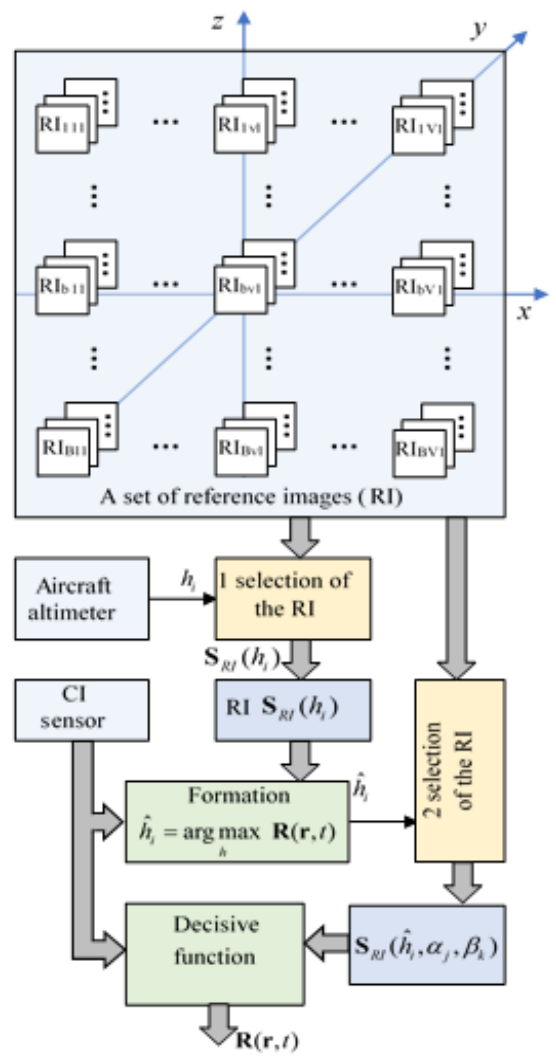

Figure 1 Block diagram of the implementation of the method of rational choice of RI

\section{Results}

4.1Model of the process of formation of the decision function

Statement of the Problem of Developing the Method and Algorithm of RI Selection in the CENS Secondary Processing System

Initial conditions. Let us consider the process of location of a high-speed maneuvering aircraft equipped with an optoelectronic CENS. An example of the image frame formation of the SS CENS placed onboard the aircraft is shown in Figure 1.

Assume that the following conditions are met:

1. The altitude of the aircraft flight and the sighting angle of the reference area vary within a wide range.

2. For simplicity, we choose SS as a natural landscape without three-dimensional objects that lead to the appearance of shadows on neighboring areas of SS.

3. We will not consider changes in brightness and/or light source position, which lead to a significant difference in the brightness set of corresponding image pixels $S_{C I}(m, n)$.

4. The CENS generates distortion-free SS images.

5. The image is described by a uniformly bounded and differentiable all over its arguments brightness, distribution function $\mathbf{S}(\mathbf{r}(t), t)$, where $\mathbf{r}(t)=(x(t), y(t))$-the shift vector in the coordinate system of the image plane.

6. CENS generates image frames (Equation 1):

$$
\begin{gathered}
\boldsymbol{\psi}_{0}, \ldots, \boldsymbol{\Psi}_{p} \\
\boldsymbol{\psi}_{0}=\boldsymbol{\psi}\left(\boldsymbol{r}(t), t_{0}\right), \ldots, \boldsymbol{\Psi}_{p}=\boldsymbol{\psi}\left(\boldsymbol{r}(t), t_{p}\right)
\end{gathered}
$$

where $t_{p}=t_{0}+\Delta t_{p} ; t_{0}, t_{p}-$ the moments of time at which the frames are formed $\boldsymbol{\psi}_{0}, \boldsymbol{\psi}_{p} ; \Delta t_{p}$ - time interval between frames $\boldsymbol{\psi}_{0}$ and $\boldsymbol{\psi}_{p}$.

At the same time, images are formed in each frame, respectively (Equation 2):

$$
\mathbf{S}_{O I_{0}}=\boldsymbol{\psi}_{0} \cap \mathbf{S}\left(\mathbf{r}, t_{0}\right), \ldots, \mathbf{S}_{O_{I_{p}}}=\boldsymbol{\Psi}_{p} \cap \mathbf{S}\left(\mathbf{r}, t_{p}\right)(2)
$$

The number of images, depending on the problem to be solved, can be different, which can provide the possibility of forming the appropriate number of DF. 
Description of the aggregate RI.

Suppose that the aircraft moves in the $x z$ plane of the $x, y, z$ coordinate system, which is associated with the SS (Figure 2).

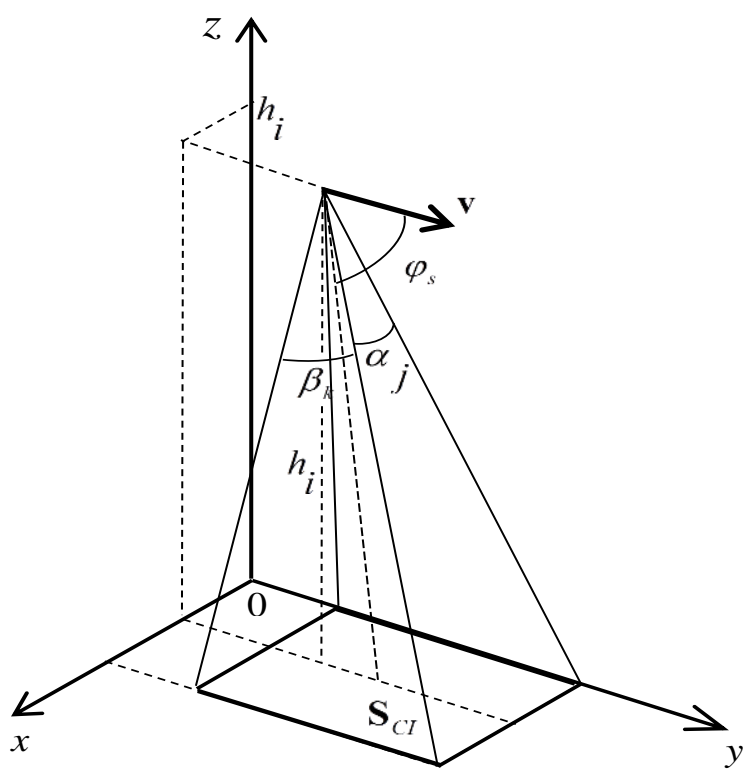

Figure 2 Geometric conditions of RI formation

The position of each partial antenna pattern (AP) is characterized by the angles $\alpha$ and $\beta$. The opening angles of the AP at the half-power level are equal in the plane along the location angle $\theta_{x}$ and $\theta_{y}-$ in the azimuthal plane. For a Gaussian approximation of the AP, its intersection with the $x y$ plane represents an ellipse. The spatial resolution of the antenna system (the width of the AP at the half-power level) $2 \theta_{0.5}=\frac{\lambda}{d_{a}}$,

where is $\lambda$-the wavelength of the receiving path; $d_{a}$ - antenna opening diameter.

In accordance with the geometric conditions and the possibility of changing the aircraft flight conditions, the formation of RI should take into account the following.

A wide range of changes in aircraft flight altitude $h_{i} \in\left[h_{\min }, h_{\max }\right]$, sighting angles $\alpha_{j} \in\left[\alpha_{\text {min }}, \alpha_{\max }\right]$, $\beta_{k} \in\left[\beta_{\text {min }}, \beta_{\max }\right]$, differences in terrain direction determined by the vector $\boldsymbol{v}$, as well as temporal changes $t_{p}$.

Consideration of these conditions necessitates the use of a set of RI (Equation 3):

$$
\begin{aligned}
& \mathbf{S}_{R I}\left(2 \theta_{0,5}, h_{i}, \alpha_{j}, \beta_{k}, v_{l}, \varphi_{s}, t_{p}\right), i=\overline{1, I}, j=\overline{1, J}, \\
& k=\overline{1, K}, l=\overline{1, L}, p=\overline{1, P}, s=\overline{1, S} .
\end{aligned}
$$

Each of the individual RI corresponds to a different matrix of brightness values of the corresponding pixels (Equation 4):

$\boldsymbol{S}_{R I}=\left\|S_{R I}(m, n)\right\|, m=1, \bar{M}, n=\overline{1, N}$,

where $M, N-$ the dimensions of RI.

Each RI from the available population is a binary image. This means that elements of the anchor object correspond to values 1 , and elements of the background 0 . For the considered RI and CI models, let us present the DF, as a result of comparing $\mathrm{CI}$ and RI, in the following form (Equation 5):

$\mathbf{R}(\mathbf{r}, t)=\mathbf{F}_{S P}\left(\mathbf{S}_{C l}(\mathbf{r}, t), \mathbf{S}_{R I}\left(2 \theta_{0,5}, h_{i}, \alpha_{j}, \beta_{k}, \mathbf{v}_{l}, \varphi_{s}, t_{p}\right)\right)$,

where $\mathbf{F}_{S P}$ - image comparison operator.

Problem statement. For the considered CI and RI models it is necessary to solve the problem of choosing one of the available sets of RI $\mathbf{S}_{R I}$ and form

a DF $\mathbf{R}(\mathbf{r}, t)$ without a complete enumeration of all possible options for comparing images.

4.2Method and algorithm of RI selection in the system of secondary processing of CENS for navigation of high-speed maneuvering aircraft

The aggregate of RI is $\left\{\mathbf{S}_{R I}\left(2 \theta_{0,5}, h_{i}, \alpha_{j}, \beta_{k}, \mathbf{v}_{l}, \varphi_{s}, t_{m}\right)\right\} \quad$ a multidimensional matrix, for the analysis of data of which the multidimensional-matrix approach is applied. It is caused by necessity of use of the software tools possessing algorithmic generality. At the same time we will notice that the multidimensional-matrix approach continues to be at the stage of its development [20]. That is why the solution of the task determines the necessity of application of some simplification. Proceeding from this, the solution of the task of choosing one of RI $\mathbf{S}_{R I}$ from the available $\{\bullet\}$ set will be performed on the basis of search of a solution providing the maximum coincidence of compared images with a minimum number of comparison operations. In other words, given the identity of the parameters of the image acquisition sensors of the RI and CI, the propagation conditions 
of the working signals and illumination, as well as the electrophysical parameters of the SS objects, the determination of the maximum match of the RI to the generated CI consists in determining the correspondence of arguments of the brightness distribution function of the compared images. That is, according to (Equation 1), it is necessary to determine those parameters from the set $\left(2 \theta_{0,5}, h_{i}, \alpha_{j}, \beta_{k}, \mathbf{v}_{l}, \varphi_{s}, t_{m}\right), \quad$ that maximally correspond to $(\mathbf{r}, t)$. In fact, the problem again is reduced to a search, which necessitates the introduction of assumptions on the constancy of a number of parameters from the population. Obviously, the vector $\mathbf{r}$, which characterizes the geometric conditions of sighting, must be matched with the closest parameters of the RI formation $h_{i}, \alpha_{j}, \beta_{k}, \mathbf{v}_{l}, \varphi_{s}$. To determine these parameters, we analyze a typical image of SS with a natural landscape. As an example, we use the image shown in Figure 3. The image was taken with a digital camera used for aerial photography from an aircraft. An overview of cameras for unmanned aircraft is given in [21]. Figure 3 to Figure 14 shows the images and the brightness distribution.

Let's take into account the recommendations made in [12]: to ensure the required high accuracy characteristics of the navigation system in conditions of changing aircraft trajectory, it is necessary and sufficient that the correlation between the individual RI was in the range from 0.5 to 0.7 . Let us simulate brightness distribution in one of velocity vector directions using MATLAB software product. As a result, we obtain the graph shown in Figure 4.

Taking into account ensuring correlation relation, let us compare similar images and brightness distribution graph obtained at angles $-80^{\circ}$ and $-70^{\circ}$, keeping all other sighting conditions the same.

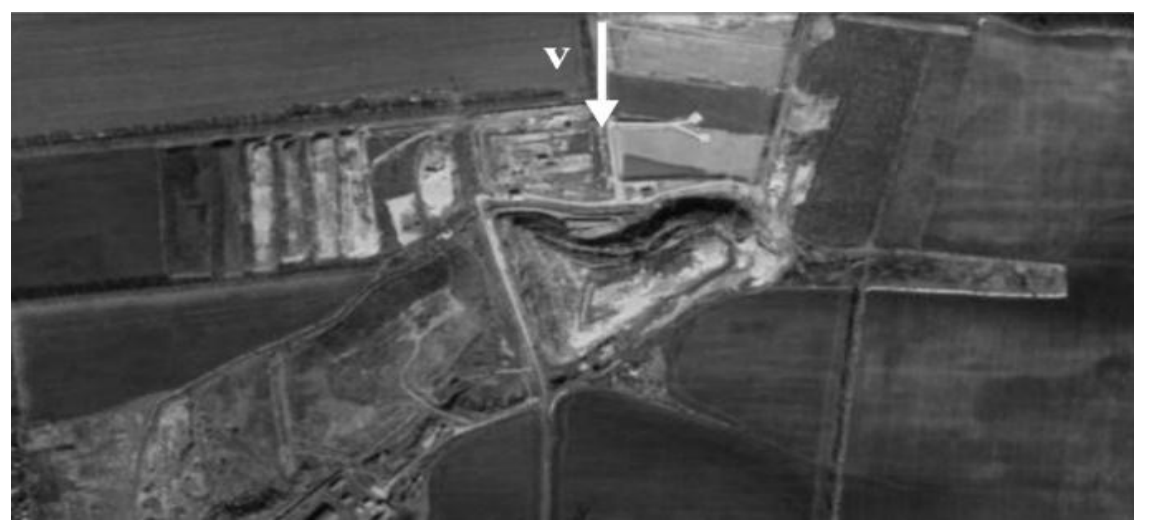

Figure 3 Image of a typical landscape at nadir from an altitude of $500 \mathrm{~m}\left(\varphi_{s}=-90^{\circ}\right)$

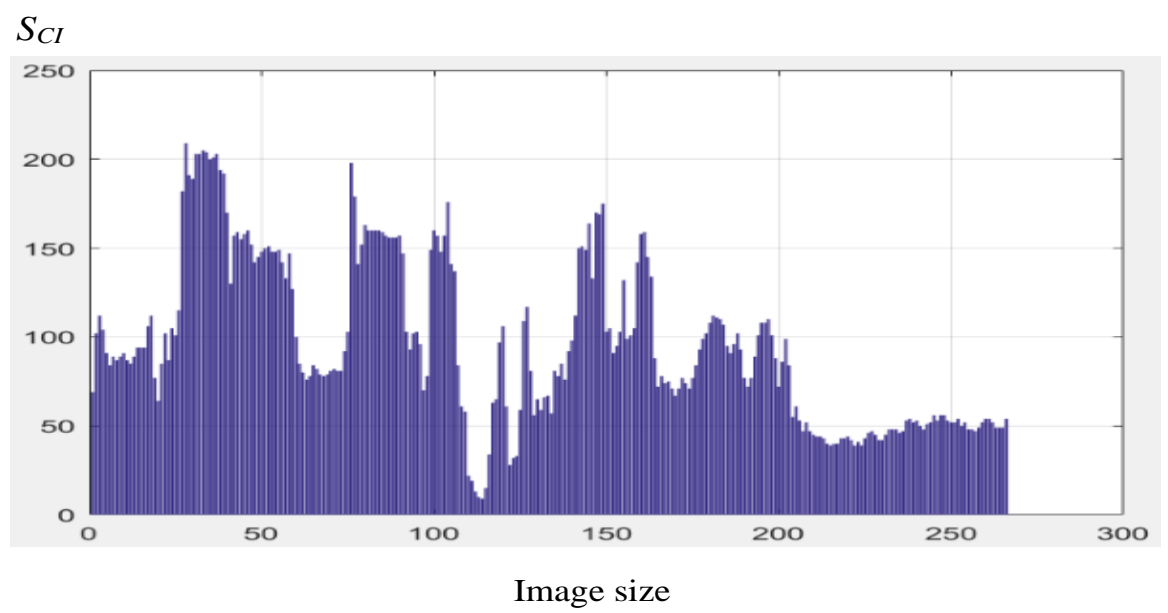

Figure 4 Brightness distribution of objects in cross section v for the CI (Figure 3) 
Comparing the brightness distribution plots of SS objects shown in Figure 4, Figure 6 and Figure 8, it is easy to see the emerging brightness shifts, which are well observed by the it in the area of its lowest value (around 115 pixels (Figure 6) and 123 pixels (Figure 8). The same pattern is repeated for smaller location angles. Assuming that the image (Figure 3) is the RI and the image (Figure 7) is the current image (frame $\boldsymbol{\psi}_{0}$ ), it becomes apparent that the estimate of the image bias of frame $\boldsymbol{\psi}_{0}$ relative to the RI frame is about 12 pixels. If we assume that CI ((frame $\left.\boldsymbol{\psi}_{1}\right)$ ) is the image (Figure 5) and compare it with the image selected as RI (Figure 3), we obtain a bias of about 5 pixels. That is, this procedure should be repeated until the components of the displacement vector $\mathbf{R}$ at the $\mathrm{n}$ step become less than the given values $\sigma_{\mathrm{x}}>0$. The decisive rule is that the RI $\mathbf{S}_{R I} \subset\left\{\mathbf{S}_{R I}\left(2 \theta_{0,5}, h_{i}, \alpha_{j}, \beta_{k}, \mathbf{v}_{l}, \varphi_{s}, t_{m}\right)\right\}$, for which the result of comparison with CI $\mathbf{R}_{n}=\underset{m}{\sup } \underset{m}{(m, n)}$, declared to be the same as the RI . The index i will take as many values as individual RI from the available population will be used. The same procedure should be performed for the second coordinate. Thus, for a fixed value of height by enumerating several variants of images, the degree of mismatch of compared images will be determined. Now consider a situation where the misalignment will be determined by a change in the altitude of the aircraft. Let us take as the basis the same section of SS in the area of objects with the lowest brightness value. The choice of this SS segment in this case is due to the convenience of visual representation of brightness distribution and its changes at different angles. The SS fragments and brightness distributions of objects obtained from a height of $250 \mathrm{~m}$ at nadir and at angles of $-80^{\circ}$ and $-70^{\circ}$ are shown in Figure 9 to Figure 14.

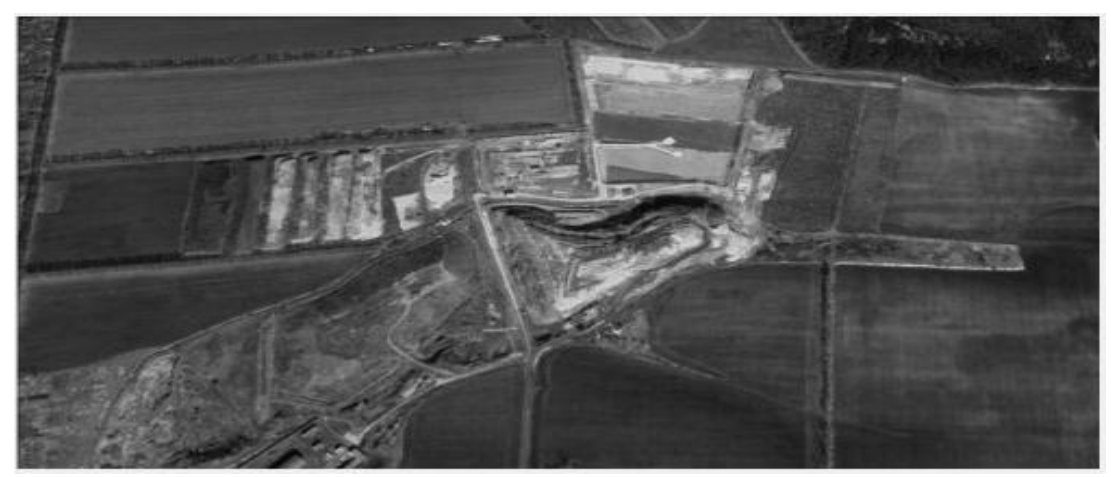

Figure 5 Image of a typical landscape at the angle of the seat $\varphi_{s}=-80^{\circ}$

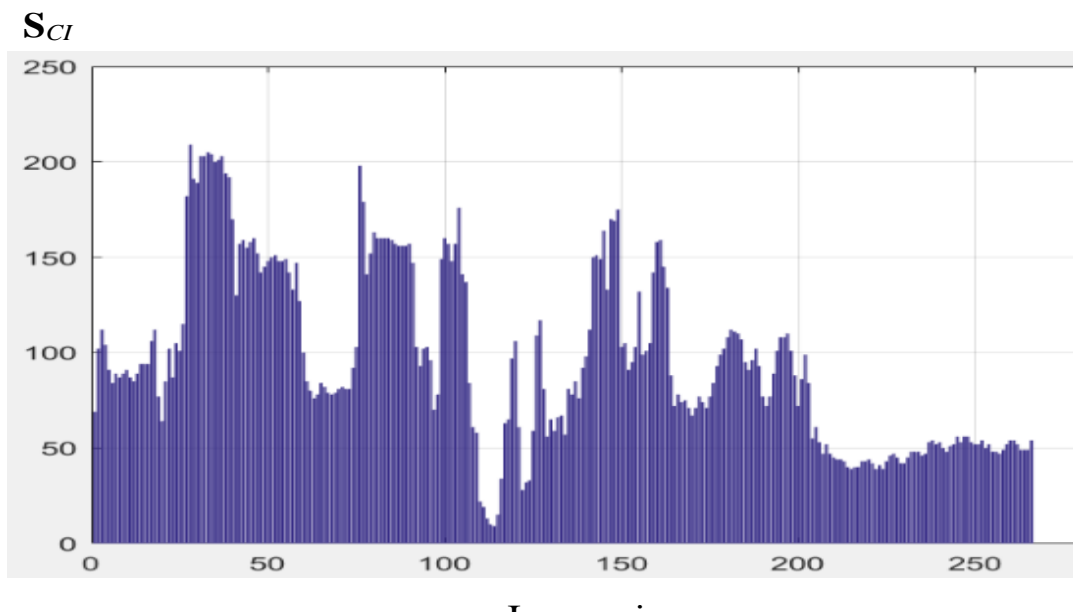

Image size

Figure 6 Brightness distribution of objects in cross section v for the CI (Figure 5) 


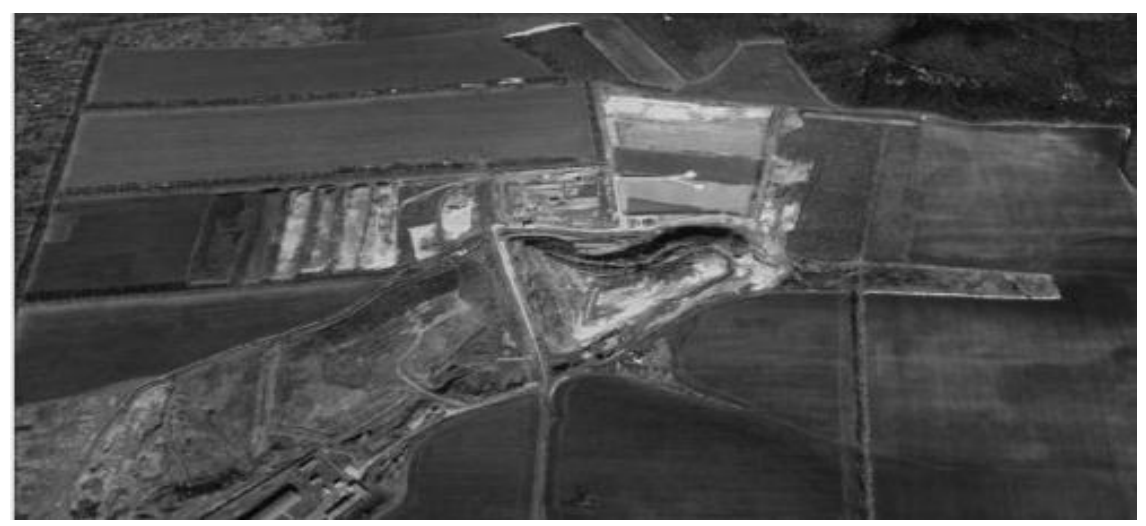

Figure 7 Image of a typical landscape at the angle of the seat $\varphi_{s}=-70^{\circ}$

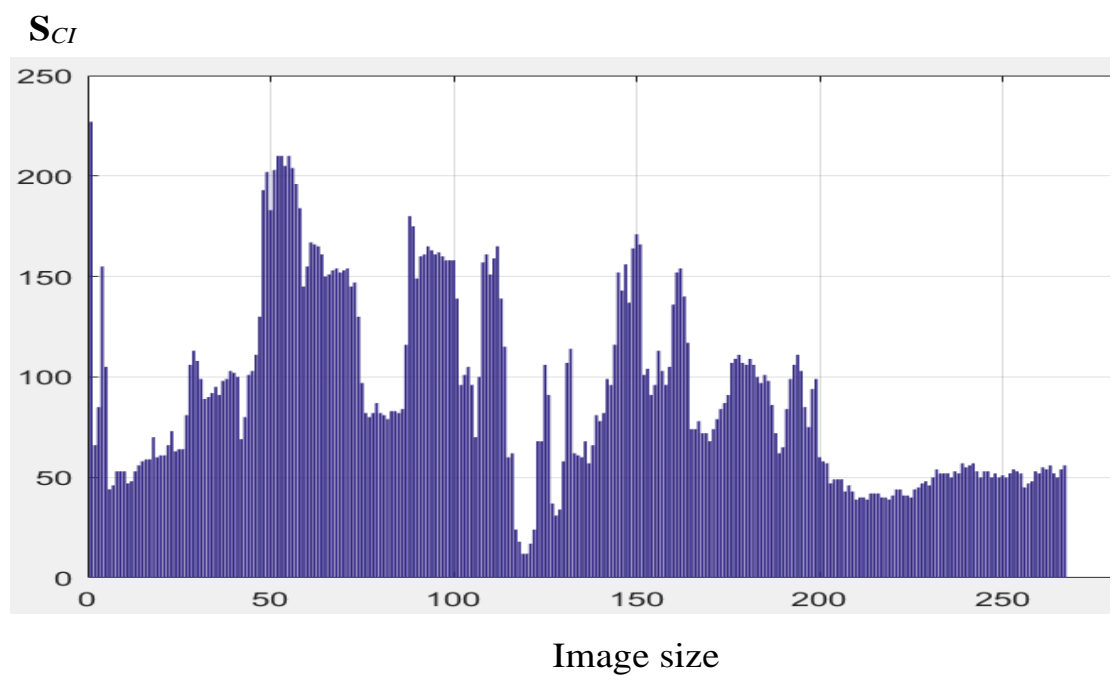

Figure 8 Brightness distribution of objects in cross section v for the CI (Figure 7)

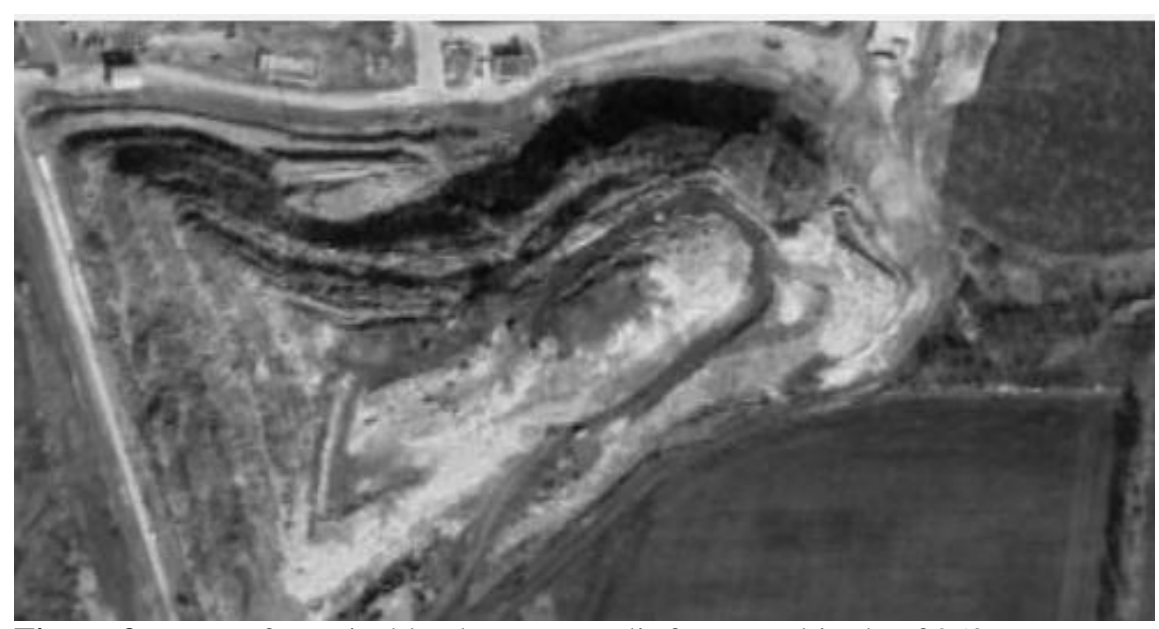

Figure 9 Image of a typical landscape at nadir from an altitude of $250 \mathrm{~m}$ 
NataliiaYeromina et al.

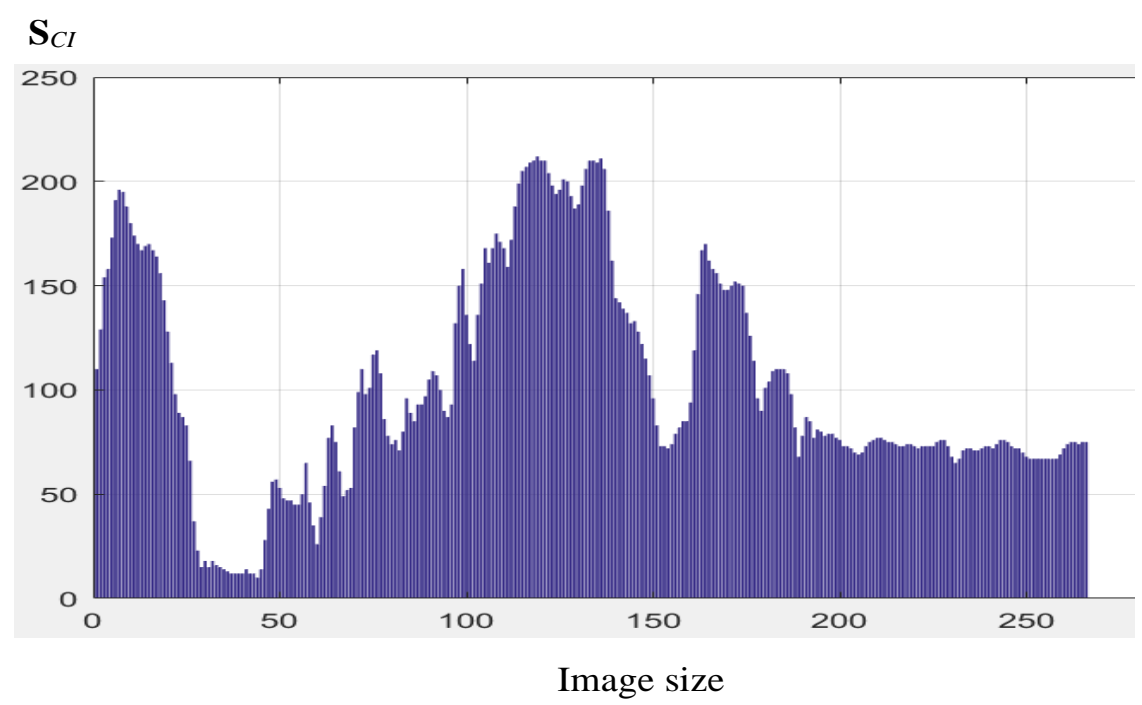

Figure 10 Brightness distribution of objects in cross section v for the CI (Figure 9)

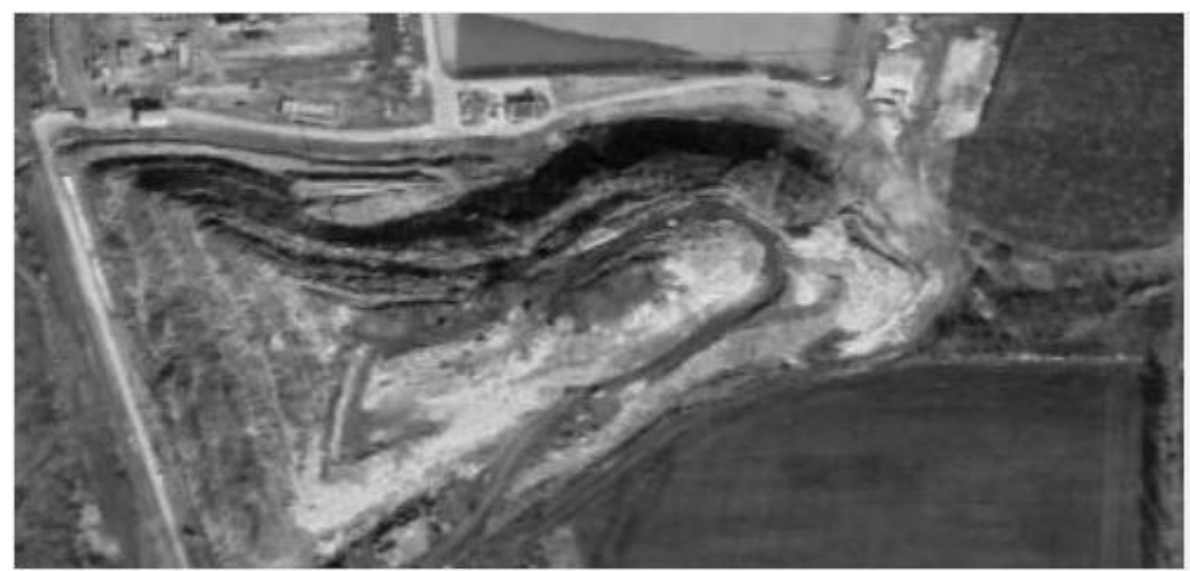

Figure 11 Image of a typical landscape at the angle of the seat $\varphi_{s}=-80^{\circ}$

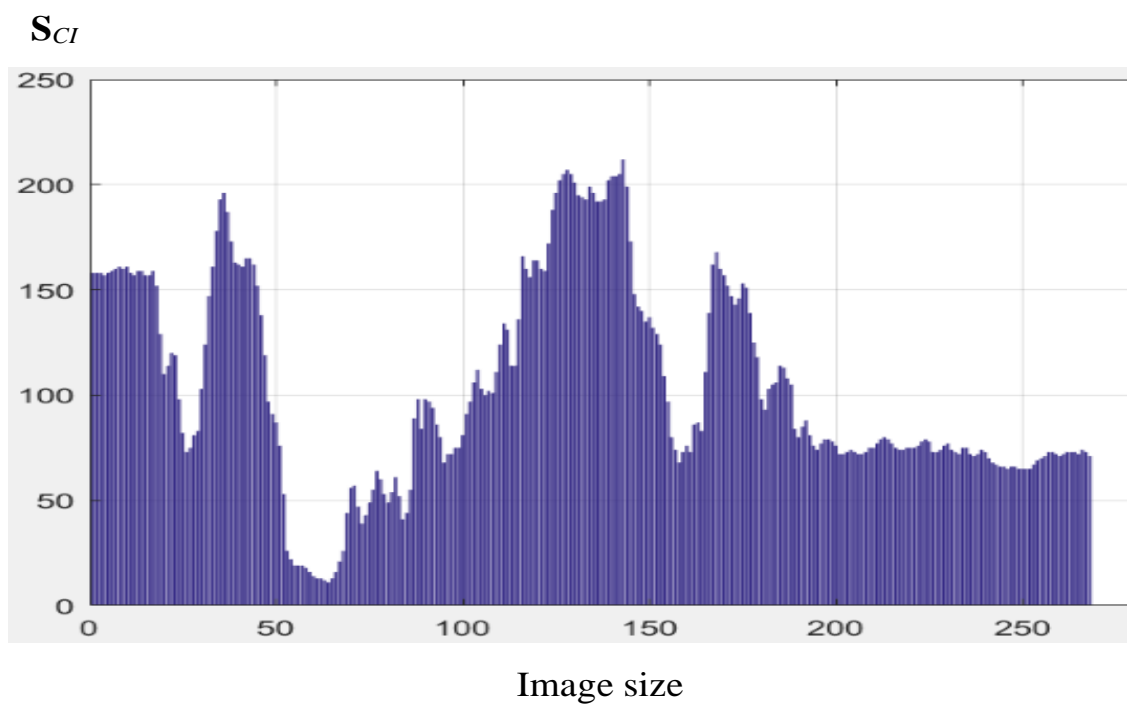

Figure 12 Brightness distribution of objects in cross section v for the CI (Figure 11) 1630 


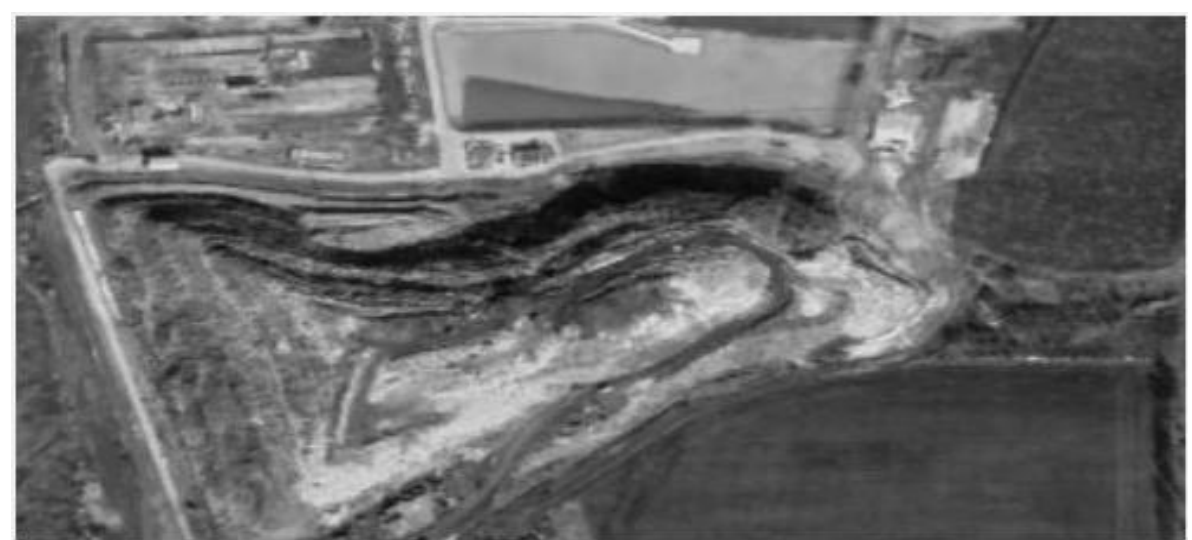

Figure 13 Image of a typical landscape at the angle of the seat the seat $\varphi_{s}=-80^{\circ}$

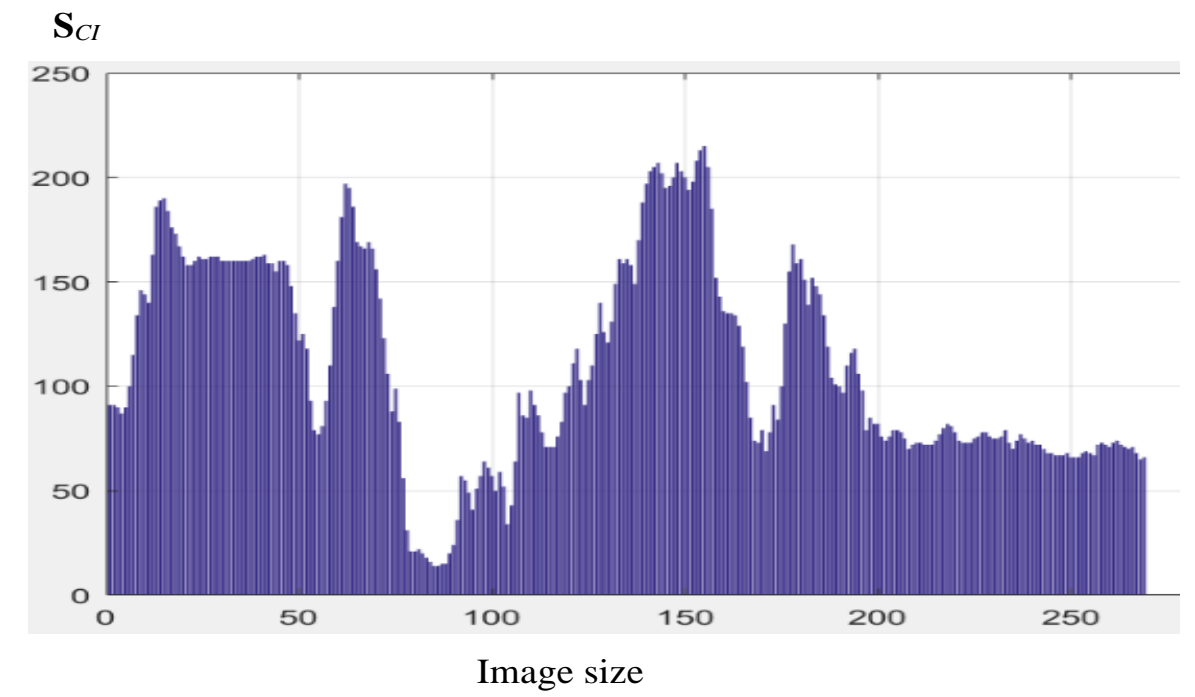

Figure 14 Brightness distribution of objects in cross section v for the CI (Figure 13)

Comparing in pairs the graphs with brightness distributions for different altitudes but the same sighting angles, it is easy to see the differences in brightness distributions. These differences are caused by the fact that with increasing sighting height the field of view naturally increases, at the same time the detail decreases, which should be taken into account when preparing the RI. The analysis of the simulation results (Figure 4, 6, 8, 10, 12, 14) shows that the choice of a fragment of RI from the available population, first of all, should be made by the parameter of height of the aircraft $h_{i}$. Since different types of UAV are equipped with altimeter, the rough selection of RI by this parameter is not difficult. In order to clarify the true altitude of the aircraft, at which the CI is formed by the navigation system, it is necessary to organize an iterative process of searching for the fragment of RI that most coincides with CI. If in the multidimensional matrix, which is a set of RI, the fragments of RI, which differ by the altitude parameter, are represented by columns, then the choice of RI is first organized by one of the columns. It is necessary to select the column based on the type of trajectory and the orientation of the CENS sensor relative to the sighted surface. You can choose the normal as the starting point. Then, the second stage begins to search for the fragment of RI which most precisely coincides with $\mathrm{CI}$ according to the angular parameters (orientation parameters). For this purpose, an iterative process is also organized, but only by matrix rows, similarly to the procedure described above. As a result, the angular coordinates, at which the fragment of the RI will have the smallest deviation from the CI, will be specified for the value of the aircraft height found at the first stage. This approach, by organizing a two-stage iterative procedure to find a fragment of RI from the available population, which most accurately matches the CI, 
allows to determine the sought RI fragment without performing a complete enumeration. The degree of deviation of the selected fragment of RI from the obtained CENS of the current image will characterize the navigational aircraft.

The algorithm of RI selection according to the above reasoning is shown in Figure 15.

In accordance with the decisive rule, the images for sighting angles of $-80^{\circ}$ and $-60^{\circ}$ were compared with the image obtained at an angle of $-90^{\circ}$. As a result, their cross-correlation functions (CCF), as shown in [12], used as a measure of similarity, were constructed. An autocorrelation function (ACF) is constructed for the $-90^{\circ}$ angle images. The comparison was performed for two heights. The results of image comparison are shown in Figure 16 and Figure 17.

Analysis of the results of autocorrelation function and cross-correlation functions (Figure 16 and Figure 17) shows that application of iterative procedure to find the largest matching of fragment of RI from aggregate with obtained CI leads to reduction of the degree of mismatch of compared images as deviation of sighting angles from normal decreases. In our case the deviation value for height $500 \mathrm{~m}$ is 0.75 at an angle of -800 and 0.91 at an angle of -600 . At these sighting angles and a height of $250 \mathrm{~m}$ the deviation of the RI from the $\mathrm{CI}$ is 0.83 and 0.92 , respectively.

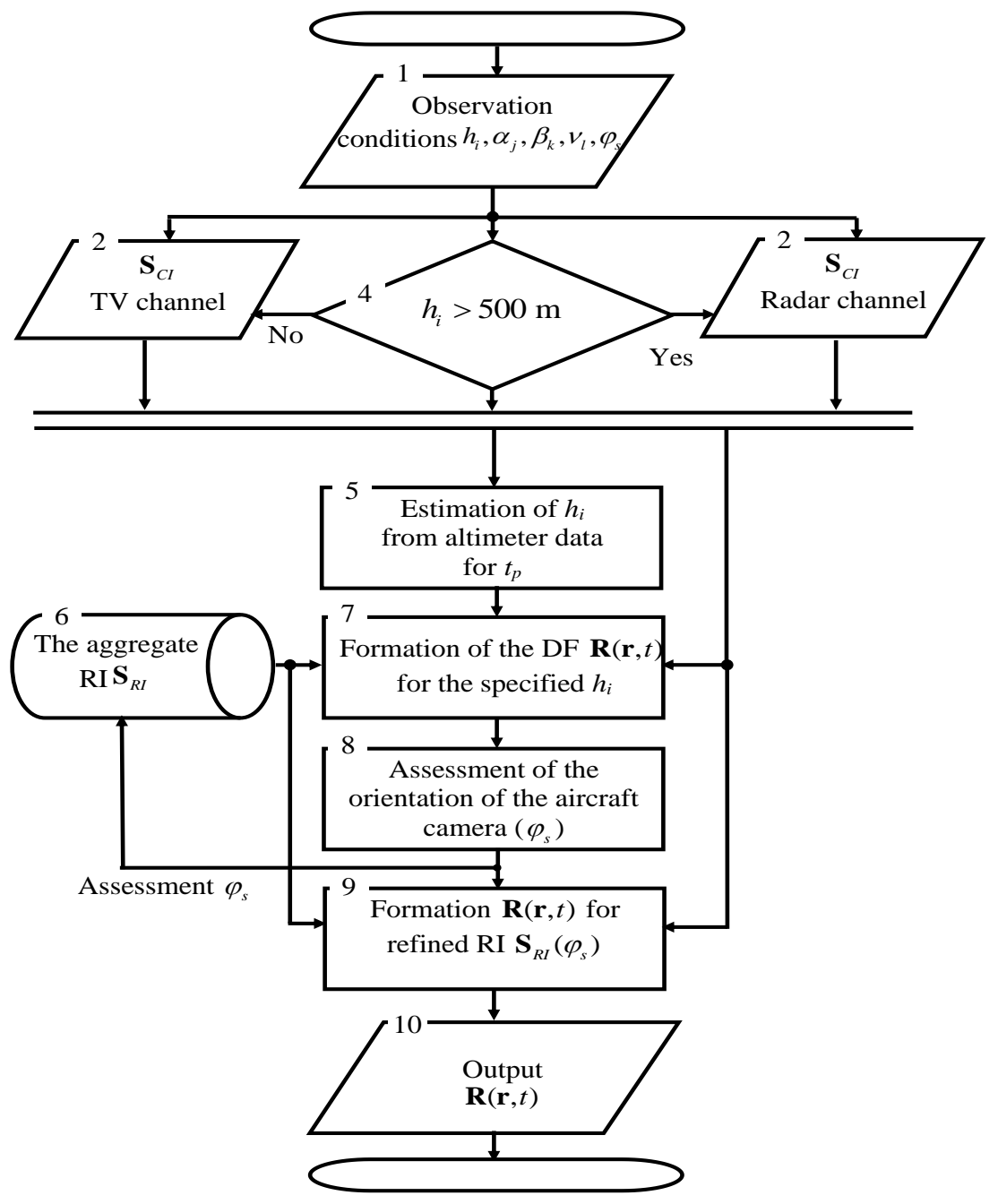

Figure 15 Algorithm of RI selection and formation of decision function 


\section{$\mathbf{R}(x)$}

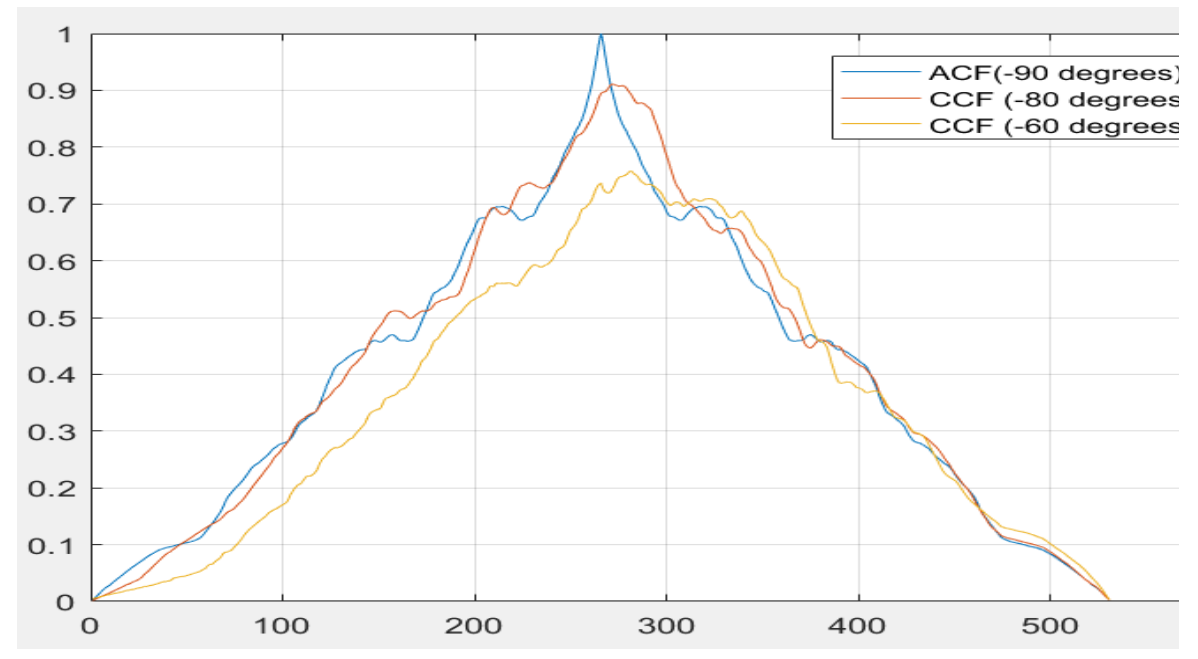

Image size

Figure 16 Results of ACF for sighting angle $\left(-90^{\circ}\right)$ and CCF for sighting angles $-80^{\circ}$ and $-60^{\circ}$ for height $500 \mathrm{~m}$

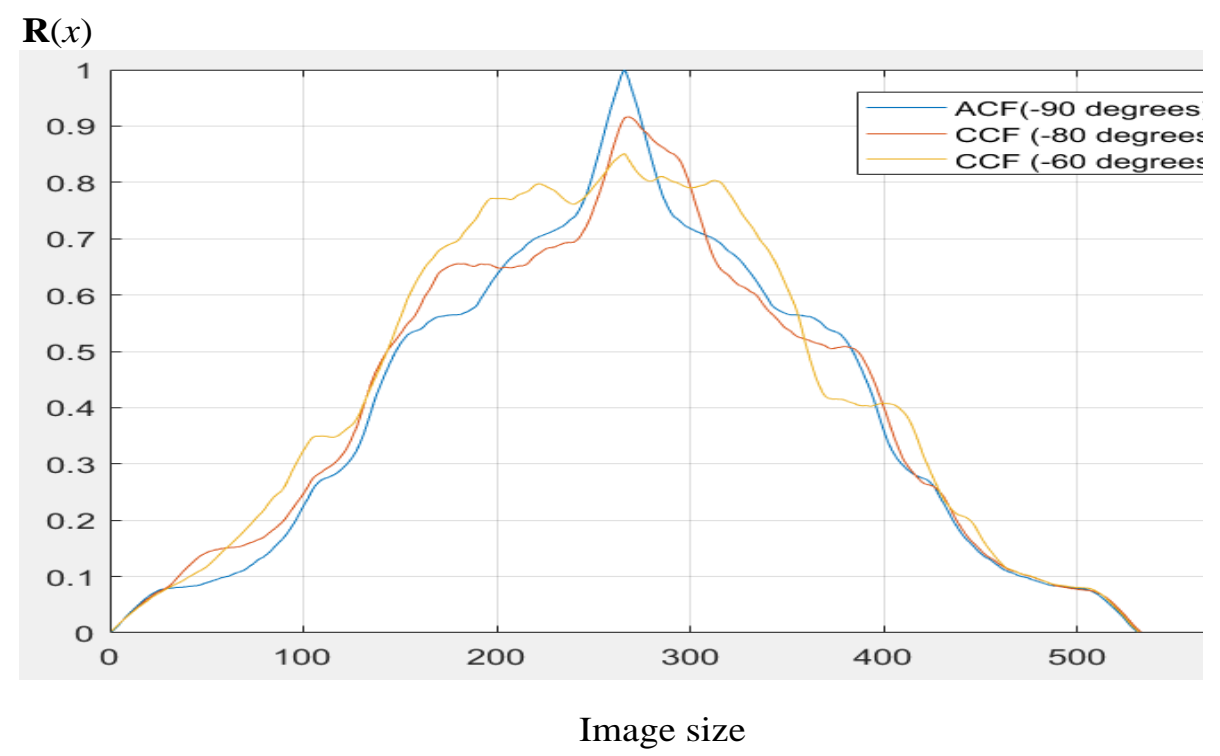

Figure 17 Results of ACF for sighting angle $\left(-90^{\circ}\right)$ and CCF for sighting angles $-80^{\circ}$ and $-60^{\circ}$ for altitude $250 \mathrm{~m}$

These results agree well with the above results of pairwise comparison of plots with brightness distributions for different altitudes. Let us evaluate the effectiveness of the proposed method in terms of reducing the computational complexity. For this purpose, we introduce an index of the relative reduction of the computational complexity of image comparison, depending on the total number of RI in the used population $W$.

Let's express this index by the ratio of the number $N_{0}$ of the complete enumeration of pairwise compared separate fragments of RI from the whole totality representing a three-dimensional matrix (by coordinates), in which each separate element represents a two-dimensional image (according to the height and orientation of the aircraft) with the current image formed by CI sensor (Figure 1) to the number $N_{1}$ of pairwise compared RI fragments used to find the RI fragment most exactly coinciding with CI, based on a two-step iterative procedure according to the developed. An example of calculating the index of relative reduction of computational complexity of determining the result of image comparison. In the 
general case, the matrix describing the set of RI (Figure 1 ) has dimensionality $B \cdot V \cdot C=W$. If to be certain the matrix of the whole set of RI has dimension $10 * 10 * 10$, then the matrix of every separate element of RI fragment has dimension $4 * 4 * 4$. The iterative procedure of searching for the fragment of RI that most closely matches CI uses 4 fragments when refining by height and 8 fragments when refining by corners of $\mathrm{CI}$ in a single instance. For the selected conditions, the total enumeration of pairwise compared images will be 4000 iterations.

When using the proposed method, the number of images compared in pairs at the first stage will be 7 iterations, and at the second - 12. Thus, for the specified calculation conditions, the index of relative reduction of computational complexity of determining the result of comparison of images will be about 210 times without deterioration in the accuracy of the CENS location

\section{Discussion}

The above study was performed using an image fragment selected at random in Google Earth. We purposely did not tie it to a specific image type in order to get relatively objective estimates of the accuracy of the CENS. In this case we took the altitudes of the aircraft $500 \mathrm{~m}$ and $250 \mathrm{~m}$, which correspond to the conditions of UAVs equipped with TV cameras. The images and the results of the CCF construction were performed by changing the sighting angles in increments of 100 , so that the reference object was within the field of view of the camera. The choice of 8 bit images made it possible to simplify the process of calculating the CCF and to ensure its universality with respect to sensors of different physical nature. The use of our proposed method for selecting an RI, as calculations show, provides a high accuracy of the CENS binding in spite of the reduction of computational operations. Since the accuracy of the CENS is determined by the width of the main lobe of the CCF, as a result of comparing the CI and RI, we modeled the process of forming the CENS solver function. The results of the numerical calculation of the CCF for the CI (Figure 3,5 , and 7), obtained from a height of $500 \mathrm{~m}$, are shown in Figure 18 to Figure 20. Figure 18 characterizes the greatest correspondence of the CI to the selected RI (RIbvc). The mismatching of CI and RI by angle is characterized by a decrease in the mutual correlation coefficient (Figure 19 and Figure 20 .), an increase in the relative level of lateral residuals, and a decrease in the steepness of the CCF in the main maximum, which is uniquely related to 1634 the accuracy of location. The results of image comparison, shown in Figure 18, show that the application of the developed method of rational choice of RI ensures the fulfillment of existing requirements for the accuracy of aircraft positioning. At the same time, the reduction of computational complexity of image comparison on the basis of the developed method provides their achievement in real time.

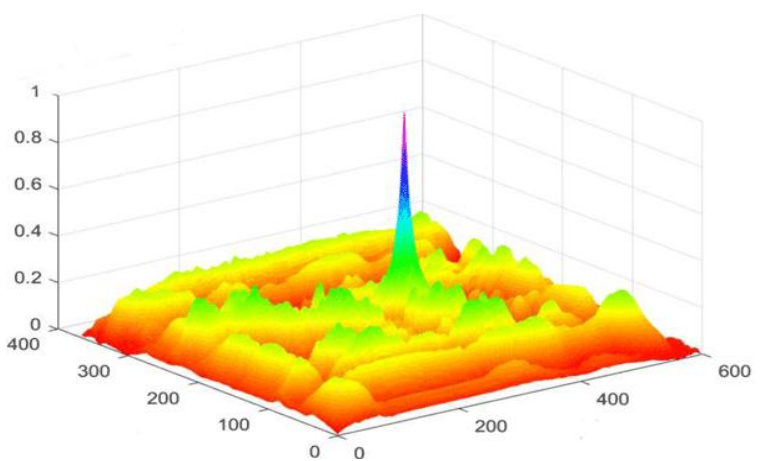

Figure 18 The cross-correlation function for the RI to Figure $3\left(\varphi_{\mathrm{s}}=-90^{\circ}\right)$

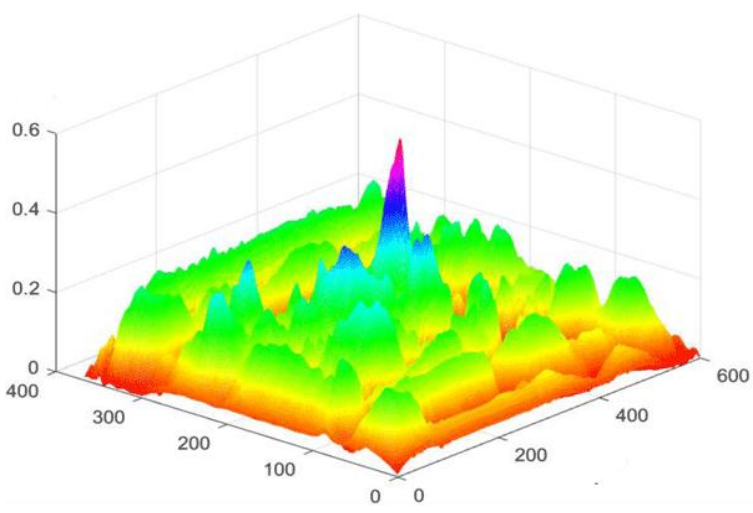

Figure 19 The cross-correlation function for the RI to Figure $5\left(\varphi_{s}=-80^{\circ}\right)$

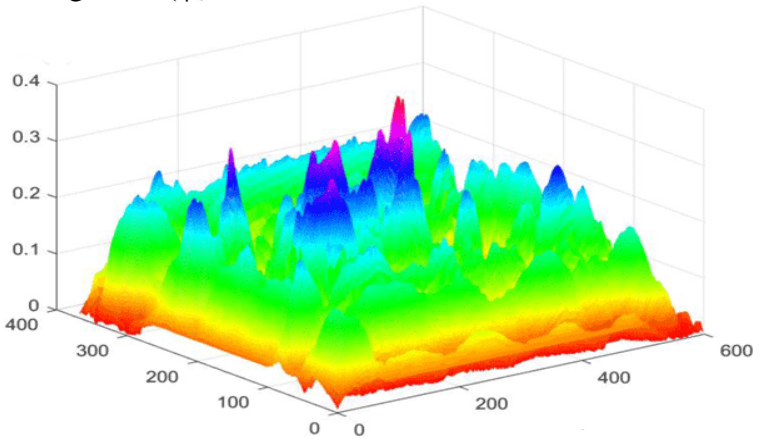

Figure 20 The cross-correlation function for the RI to Figure $7\left(\varphi_{\mathrm{s}}=-60^{\circ}\right)$

The developed method and based on it, the algorithm for selecting RI from the available population in 
order to increase the performance of the secondary image processing system of CENS can be used on aircraft with real-time replanning of the route and the trajectory of the flight. The implementation of the algorithm in the aircraft navigation systems with different requirements for the accuracy characteristics necessitates the selection of the size of the RI under the conditions of convergence of the iteration procedure. In this case, the threshold by which the selection procedure of digital signals and, accordingly, the comparison with CI is performed, it is necessary to choose based on the sensitivity and resolution of the primary processing system. This must be taken into account when using the proposed approach to the selection of RI from the available population in the CENS of combined type using a single universal RI. Besides, the proposed method allows eliminating the ambiguity when choosing RI from the population when using a single reference base for combined CENS, equipped with sensors with different spatial resolution. The procedure of comparison of image fragments using as an informative parameter the brightness (and/or reflectance) of objects is expedient to carry out by the indicator of the mutual correlation function.

At the same time, it should be noted that this study has a number of limitations. Firstly, the application of this method for the positioning of the aircraft using sighting surfaces with developed infrastructure, high object saturation and the presence of high-rise structures requires additional research. This is due to the influence of shadow effects, conditions, and degree of illumination. In addition, it is necessary to take into account the possibility of getting into the sighting area of objects close to the reference object in terms of brightness distribution, which may be due to the structural similarity of objects, as well as the presence of closing angles of individual objects. Secondly, the use of sensors of different physical nature for the positioning of the aircraft makes it necessary to take into account the differences in the size of the sighting area and their resolution, which will lead to differences in the generated CI. A complete list of abbreviations is shown in Appendix I.

\section{Conclusion}

The model for describing the process of forming the decisive function CENS was further developed. The peculiarity of the model is to take into account the factors affecting the construction of the CENS itself and the final result of its operation, associated with a complex trajectory and high flight speed of the aircraft. The necessity to find the solution for the selection of the RI from the set of images during the DF formation was justified. On the basis of the model the problem of developing a method and algorithm for the selection of the image data in the secondary processing system of the CENS was formulated. The results of the development of the method and algorithm for the rational choice of RI are presented. The method is based on a two-step procedure for determining the fragment of RI from the available onboard population to clarify the location of the aircraft equipped with an autonomous CENS. The implementation of the two-step procedure allows us to determine the true location of the aircraft with high accuracy while significantly reducing the computational complexity of image comparison. It is shown that the implementation of the method makes it possible to reduce the computational complexity of image comparison by several tens of times. Numerical estimation of the gain for the selected computational conditions close to the real ones was 210 times.

\section{Acknowledgment}

None.

Conflicts of interest

The authors have no conflicts of interest to declare.

\section{References}

[1] https://elibrary.ru/item.asp?id=41726603. Accessed 26 October 2021.

[2] Shivrinsky VN. Onboard computer systems for navigation and aircraft navigation. Lecture Notes Ulyanovsk : Ural State Technical University, 2010.

[3] Antyufeev V. Matrix radiometric correlationextreme navigation systems for aircraft: monograph Ukraine. Kharkov: KhNU VN Karazin.

[4] Scaramuzza D, Achtelik MC, Doitsidis L, Friedrich F, Kosmatopoulos E, Martinelli A, et al. Visioncontrolled micro flying robots: from system design to autonomous navigation and mapping in GPS-denied environments. IEEE Robotics \& Automation Magazine. 2014; 21(3):26-40.

[5] https://cyberleninka.ru/article/n/problemnye-aspektysistemy-kombinirovannogo-videniya-letatelnyhapparatov. Accessed 26 October 2021.

[6] Loginov AA, Muratov ER, Nikiforov MB, Novikov AI. Reducing the computational complexity of image matching in aviation vision systems. Dynamics of Complex Systems. 2015:33-40.

[7] http://doc.knigi-x.ru/22raznoe/182387-1mezhgosudarstvenniy-aviacionniy-komitetaviacionniy-registr-rukovodstvo-315-minimalnimstandartam-harakteristik-aviac.php. Accessed 26 October 2021.

[8] Elesina S, Lomteva O. Increase of image combination performance in combined vision systems using genetic 
algorithm. In Mediterranean conference on embedded computing 2014 (pp. 158-61). IEEE.

[9] Sotnikov A, Tarshyn V, Yeromina N, Petrov S, Antonenko N. A method for localizing a reference object in a current image with several bright objects. Eastern European Journal of Advanced Technology. 2017; 3(9):68-74.

[10] Yeriomina N, Petrov S, Tantsiura A, Iasechko M, Larin V. Formation of reference images and decision function in radiometric correlation-extremal navigation systems. Eastern European Journal of Advanced Technologies. 2018; 4(9): 27-35.

[11] Tymochko O, Ttystan A, Ushan V, Yeromina N, Dmitriiev O, Mazharov V, et al. The synthesis of the reference image and algorithms for vehicle navigation systems. International Journal of Emerging Trends in Engineering Research. 2020; 8(3):853-8.

[12] Sotnikov O, Kartashov VG, Tymochko O, Sergiyenko $\mathrm{O}$, Tyrsa V, Mercorelli P, et al. Methods for ensuring the accuracy of radiometric and optoelectronic navigation systems of flying robots in a developed infrastructure. In machine vision and navigation 2020 (pp. 537-77). Springer, Cham.

[13] Yeromina N, Petrov S, Antonenko N, Vlasov I, Kostrytsia V, Korshenko V. The synthesis of the optimal reference image using nominal and hyperordinal scales. International Journal of Emerging Trends in Engineering Research. 2020; 8(5):2080-4.

[14] Liashko O, Klindukhova V, Yeromina N, Karadobrii $\mathrm{T}$, Bairamova $\mathrm{O}$, Dorosheva A. The criterion and evaluation of effectiveness of image comparison in correlation-extreme navigation systems of mobile robots. International Journal of Emerging Trends in Engineering Research. 2020; 8(6):2841-7.

[15] NataliiaYVS, Chukanivskyi D, Zadkova O, Brodova $\mathrm{O}$, Levchenko $\mathrm{O}$. The method of iterative formation of selective reference images. International Journal of Emerging Trends in Engineering Research. 2020; 8(7): 3753- 9.

[16] Yeromina N, Petrov S, Samsonov Y, Pisarevskiy S, Kaplun S, Vlasenko I. The simulation and performance evaluation of adaptive algorithm of image comparison in correlation-extreme navigation systems. International Journal of Emerging Trends in Engineering Research. 2020; 8(8):4146-51.

[17] Vorobiov O, Yeromina N, Petrov S, Ivashcuk O, Ivansky V, Pavlunko M, et al. The study of accuracy characteristics of information extraction system under conditions of change of state of the working signals propagation path and a-priori uncertainty about the informative parameters of objects on the sighting surface. International Journal of Emerging Trends in Engineering Research. 2020; 8(9):5740-5.

[18] Tymochko O, Berezhnyi A, Matiushchenko O, Trystan A, Kryzhanivskyi I, Sotnikov O. Vehicles while monitoring behavior of dynamic objects in a forest-steppe area. International Journal of Emerging Trends in Engineering Research. 2020; 8(7):3208-15.
[19] Yeromina N, Kurban V, Mykus S, Peredrii O, Voloshchenko O, Kosenko V, et al. The creation of the database for mobile robots navigation under the conditions of flexible change of flight assignment. International Journal of Emerging Technology and Advanced Engineering. 2021; 11(5):37-44.

[20] Sokolov NP. Introduction to the theory of multidimensional matrices. Nukova Dumka, Kiev. 1972.

[21] Kostyk AS. Features of aerial photography with ultralight unmanned aerial vehicles. Omsk Scientific Herald. 2016:236-40.

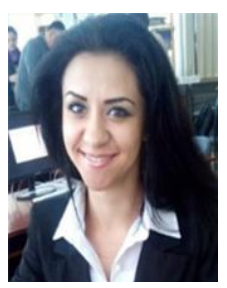

NataliiaYeromina senior lecturer of the department of electronic computers, deputy dean of the faculty of computer engineering and control, candidate of technical sciences, member of the NURE alumni association. She obtained his Master's degree in Automated Control Systems from Ukrainian Engineering Pedagogics Academy (2007), Kharkiv, Ukraine. Master's degree, Kharkiv National University of Radio Electronics, specialty "Computer Engineering", Candidate of Technical Sciences with a degree in Radio Engineering and Television Systems (2018). She has 11 years of teaching experience. She has published more than 60 research papers in national/international journals and conferences. Her research interests are Engineering, Image Processing, Machine Vision, Robotics, Signal Processing in Radar Systems and High-Precision Navigation of Unmanned Aerial Vehicles.

Email: ereminaport@gmail.com

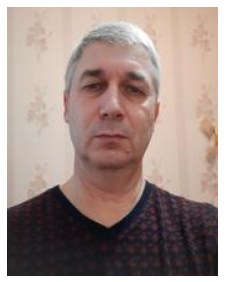

Volodymyr Tarshyn is a Professor and Head of the Department of Armament of Radar Troops, Ivan Kozhedub Kharkiv University of Air Force. He has published more than 100 other research papers in national/international journals and conferences. Signal Processing in Radar Systems and HighPrecision Navigation of Unmanned Aerial Vehicles are the area of interest.

Email:vratar-73@ukr.net

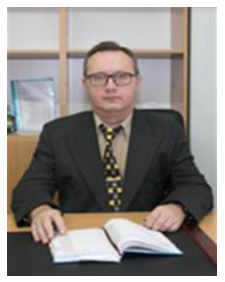

Sergey Petrov obtained his Master's degree in Automated Control Systems from Kyiv Military Institute of Control and Communications, Kyiv, Ukraine. He has 13 years of teaching experience in the Ukrainian Engineering Pedagogic Academy, Kharkiv, Ukraine. $\mathrm{He}$ has published research papers in national/international journals and conferences. His research interests are Automatic Guided Vehicles, Projectiles and Small Arms.

Email: psv_topol@ukr.net 
Valery Samoylenko, obtained his Bachelor's degree in Military science and Master in Leadership, administration and security of the Interior Troop formations from the National Academy of National Guard of Ukraine, Kharkiv, Ukraine. He has 7 years of teaching experience in National Academy of National Guard of Ukraine. He has published research papers in national/international journals and conferences. His research interests are Mobile robots, Correlation-extreme Navigation Systems and Weapons Training.

Email: samoylenko.valeriy1007@gmail.com

Iryna Tabakova obtained her Bachelor's degree in Computer-aided Design Systems from Kharkov Technical University of Radio Electronics and Master's degree in Publishing and Printing from Kharkiv National University of Radio Electronics. She got PhD for her work in Applied Geometry and Engineering Graphics from Bohdan Khmelnytskyi Melitopol State Pedagogical University. She has more than 15 years of teaching experience. She teaches courses: "Engineering and computer graphics", "Technical mechanics", "Units and mechanisms of printing equipment". She has guided many undergraduate students for their final year projects. She has published more than 40 research papers in various journals and national/international conferences. Her research interests are Engineering and Computer Graphics, Geometric Modeling, Image Processing, Machine Vision and Robotics.

Email: iryna.tabakova@nure.ua

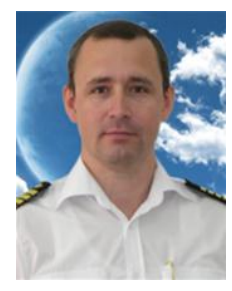

Dmitriiev Oleh, Doctor of Engineering Sciences, defended his on specialty «Information technologies» from Cherkasy state technological university. The academic title of associate professor, was awarded by the National Aviation University, Kyiv. He got Ph.D. of «Navigation and Traffic Management» from at the Kirovograd Flight Academy of the National Aviation University. From 2014 to the present, he heads the Department of Flight Operations, Aerodynamics and Flight Dynamics. He manages the scientific work of graduate students, teach courses "Flight operation of aircraft", "Principles of flight", "Flight performance". Co-author of four monographs and four tutorials. He has published more than 60 other research papers in national / international journals and conferences. His research interests are Flight Dynamics, Decision Support Systems and Navigation Systems.

Email: Dmitronik70@i.ua

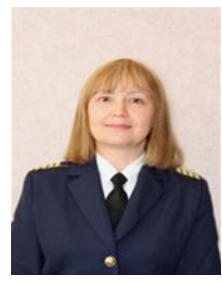

Kateryna Surkova, PhD, Docent, Department of Information Technology Flight Academy of the National Aviation University. Education: Kyiv Institute of Civil Aviation Engineers, specialty "Electronic Computers", qualification of systems engineer. She got PhD for her work on «Methods of improving the spatial abilities of the flight crew» from the Ukrainian Engineering Pedagogics Academy, Kharkiv. She has 18 years of teaching experience in aviation academy. K. Surkova has guided many postgraduate and undergraduate students for their projects. She has published more than 120 research papers in national / International journals and conferences. Her research interests are modeling of Professional Activity and Training of Aviation Specialists, Development of Electronic Learning Tools. Email: eskirua@gmail.com

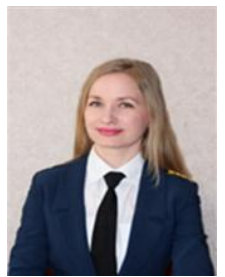

Danylko Oksana, is graduated in 2004 from the Kirovograd State Pedagogical University with a degree in «Pedagogy and Methods of Secondary Education. Mathematics». In 2011 she got $\mathrm{PhD}$ on specialty 13.00.04 - Theory and methodology of vocational education for her work «Formation of the intellectual culture of future teachers of the physics and mathematics cycle by means of information technology».In 2021 awarded the academic title of Associate Professor of the Department of Information Technologies. Author of more than 60 scientific and educational-methodical works.

Her research interests are Modeling the Professional Training of Future Flight Operator Managers.

Email: danylkoksana20@gmail.com

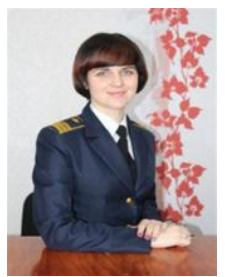

Kushnierova Nadiia, obtained her Bachelor's degree in Flight Academy of the National Aviation University, specialty - "Air Traffic Services". She got Ph.D on specialty 05.22.13 Navigation and traffic control for her work "Methods and models of synthesis of the system for forecasting accidental situations on board of aircraft on the basis of a wandering diagnostic core". Since 2016, the head of the Department of Air Navigation. Head of scientific research work: "Study of the conditions for the introduction of navigation in Ukraine, based on performance characteristics (PBN)". She is the author of more than 40 publications, including 4 monographs, 5 study guides. Her research interests are Navigation and Traffic Control, Improving the Functional Reliability of Navigation Systems and Forecasting Abnormal Situations.

Email: nadiiakushnerov@gmail.com

Soroka M. Y. obtained his Bachelor degree in Aviation and Astronautic and Masters in Air Traffic Service from State Flight Aviation Academy, Kirovograd, Ukraine. He got $\mathrm{PhD}$ in Navigation and Motion Control for his work "Methods of building a multi-agent environment of intelligent training system for training air traffic controllers" from Flight Academy of National Aviation University, Kropyvnytskyi, Ukraine. He has 16 years of teaching experience in Flight Academy. He has guided many undergraduate cadets for their final year projects. He has published research papers in various journals and national / international conferences. His area of interest 
NataliiaYeromina et al.

includes Aviation Simulators, Data Mining Methods and Artificial Intelligence.

Email: s_mike@ukr.net

Salo N. A. obtained her Bachelor degree in Aviation and Astronautic and Masters in Air Traffic, Service from State Flight Aviation Academy, Kirovograd, Ukraine. She got Ph.D in Navigation and Motion Control for her work "Methods of building an organizational system for training air traffic controllers to increase the level of their competence" from Flight Academy of National Aviation University, Kropyvnytskyi, Ukraine. She has 9 years of teaching experience in Flight Academy. She has guided a few undergraduate cadets for their final year projects. She has published research papers in various journals and national / international conferences. Her area of interest includes Aviation Simulators, Data Mining Methods and Artificial Intelligence.

Email: natal6ka9@gmail.com

Oleksandr Chumak, graduated from the National Law, University named after Yaroslav the Wise in 2019. Master's degree in law. Has been working in the legal field for more than two years in the area of aircraft navigation.

Email: chumak314253@gmail.com

\section{Appendix I}

\begin{tabular}{lll}
\hline $\begin{array}{l}\text { S. } \\
\text { No. }\end{array}$ & Abbreviations & Description \\
\hline 1 & ACF & Autocorrelation Function \\
\hline 2 & AP & Antenna Pattern \\
\hline 3 & CCF & Correlation Functions \\
\hline 4 & CENS & $\begin{array}{l}\text { Correlation-Extreme Navigation } \\
\text { System }\end{array}$ \\
\hline 5 & CI & Current Image \\
\hline 6 & DF & Decisive Function \\
\hline 7 & FINS & $\begin{array}{l}\text { Freeform Inertial Navigation } \\
\text { Systems }\end{array}$ \\
\hline 8 & GPS & Global Positioning System \\
\hline 9 & INS & Inertial Navigation Systems \\
\hline 10 & MAV & Micro-Aviation Vehicles \\
\hline 11 & RI & Reference Image \\
\hline 12 & SS & Sighting Surface \\
\hline 13 & TVS & Technical Vision Systems \\
\hline 14 & UAV & Unmanned Aerial Vehicles \\
\hline
\end{tabular}

